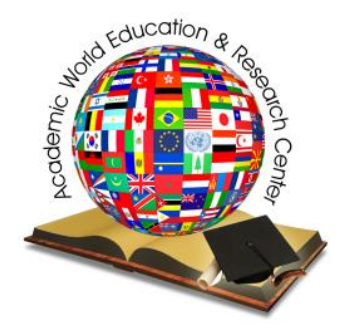

\title{
The Design and Implement of Mobile Heath Management Software Base on the Android Platform
}

Yuanqing Liu *

Minghui Wu

Honglun Hou

Suggested Citation:

AWERProcedia Information Technology \& Computer Science Proceedings of $3^{\text {rd }}$ World Conference on Information Technology

Abstract 


\section{Introduction}

\section{The overall framework of the health management platform}

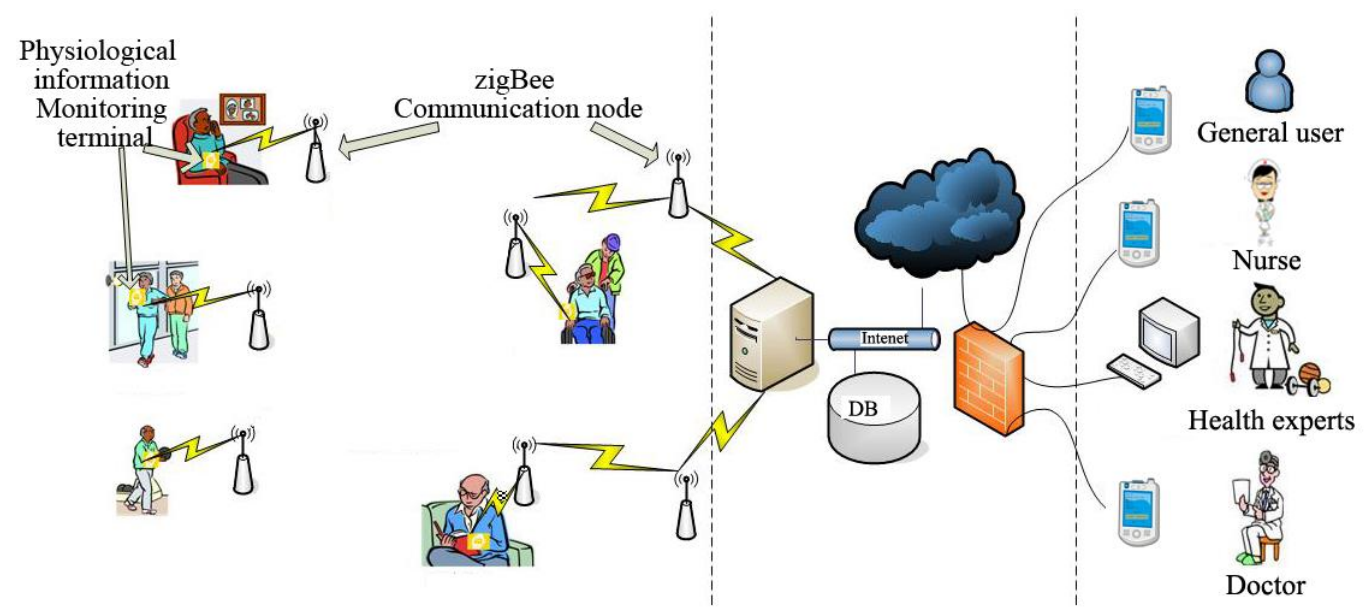


3.The analysis and design of the mobile health management software

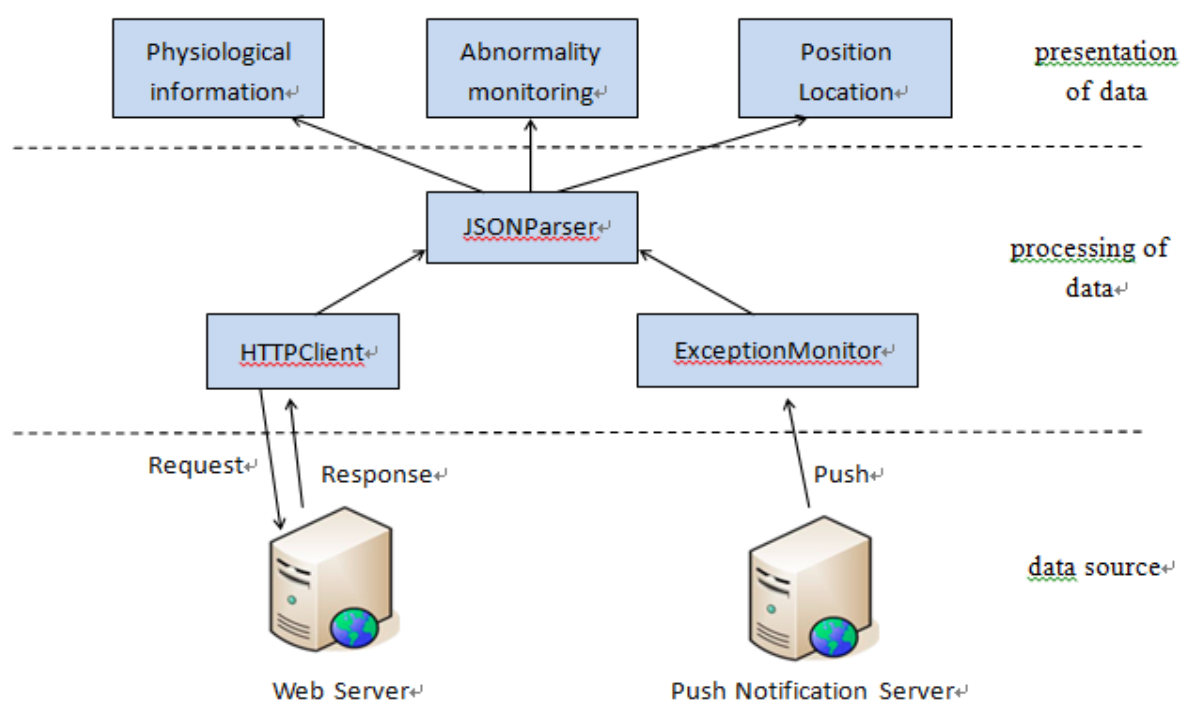

3.1. The data source 
3.2. The Data Processing

3.3. The data presentation

4.The implement of the intelligent mobile health management terminal

4.1. The roles management of people 
4.2. The physiological information

4.3. The time remind

4.4. The interactions of users 

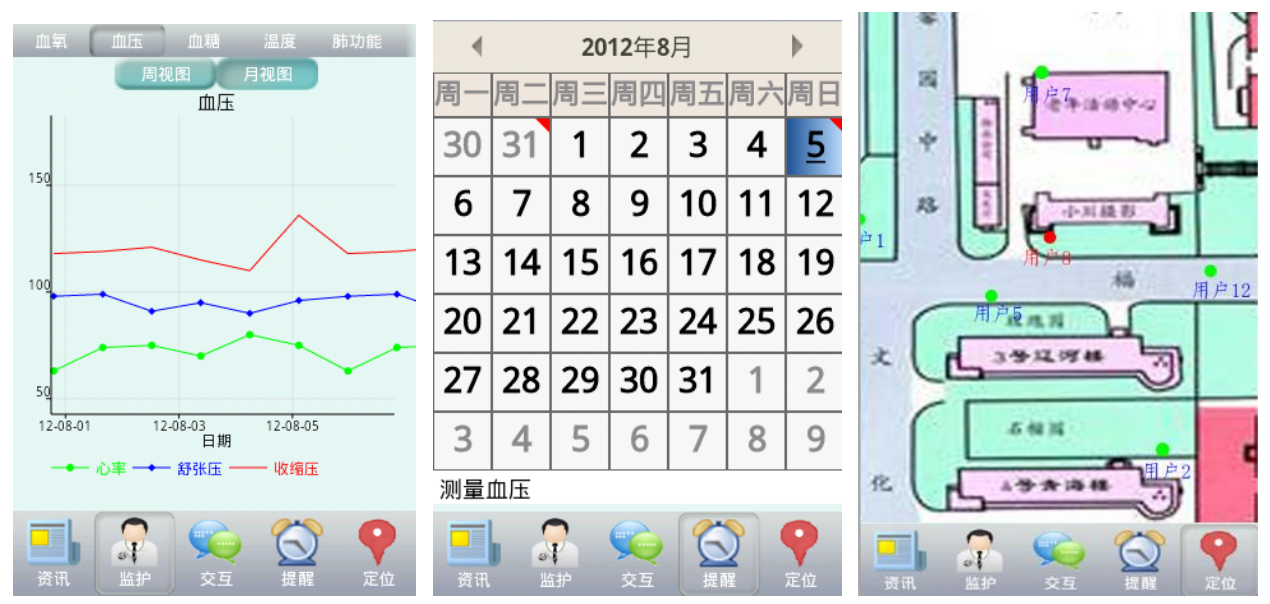

\section{Conclusions}

\section{Acknowledgements}

\section{References}


-

Journal of Public Health Management, 28 (3) ,254-256

. Chinese 